\title{
Следы поля напряжений северо-восточного сжатия на Кольском полуострове (центральная часть Мурманской области)
}

\author{
Бондарь И.В., Маринин А.В.
}

Институт физики Земли им. О.Ю. Шмидта РАН, Москва, bond@ifz.ru

Аннотация. Изучение полей напряжения на территории Кольского полуострова проводилось многими исследователями с применением различных тектонофизических методов. И как в пределах локальных геологических объектов (Печенгская структура, Хибинский массив), так и на всей территории Кольского полуострова фиксируется поле напряжения северо-западного и западного сжатия. Авторами данной статьи, по результатам многочисленных полевых экспедиций, удалось обнаружить следы поля напряжения северовосточного сжатия, а также на основании некоторых фактов предположить более молодой возраст поля напряжения северо-восточного сжатия, относительно выделяемых ранее полей напряжения.

Ключевые слова: Поле напряжения, северо-восточное сжатие, структурные парагенезы, зеркало скольжения, малые структурные формы, Кольский полуостров.

\section{Traces of the stress field of the north-eastern compression on the Kola Peninsula (central part of the Murmansk region)}

\author{
Bondar I.V., Marinin A.V. \\ Schmidt institute of physics of the earth of the RAS, Moscow, bond@ifz.ru
}

\begin{abstract}
The study of stress fields on the area of the Kola Peninsula was carried out by many researchers using various tectonophysical methods. And both within the local geological objects (the Pechenga structure, the Khibiny massif) and throughout the Kola Peninsula, the stress field of the north-western and western compression is recorded. The authors of this article, based on the results of numerous field expeditions, managed to find traces of the stress field of the north-eastern compression, and also on the basis of some facts to assume a younger age of the stress field of the north-eastern compression, relative to the stress fields previously allocated.

Key words: Stress field, north-east compression, structural parageneses, slickenside, small structural forms, Kola Peninsula.

\section{Расположение района и геологическая характеристика}

Район исследования расположен на Кольском полуострове и охватывает территорию от Ковдорского массива на западе до Хибинского массива на востоке (рис. 1).

Исследуемый район расположен в северной части Беломорского геоблока, претерпевшего в архее и раннем протерозое многочисленные складчатые и разрывные деформации, а также мигматизацию и гранитизацию. В пределах мегаблока широко развиты тоналитовые гнейсы, амфиболиты и высокоглиноземистые гнейсы беломорской серии (Государственная..., 2007). Часть точек наблюдения находятся в пределах Имандра-Варзугской шовной зоны.
\end{abstract}

\section{Методика исследования}

В ходе полевого изучения малых структурных форм в некоторых обнажениях удается фиксировать плоскости тектонических трещин (зеркал скольжения) на которых наблюдаются два (или более) направления борозд скольжения, часто свидетельствующих о разных кинематических типах этих зеркал скольжения (со взбросовой, сбросовой, право- или левосдвиговой кинематикой).

В ходе наших полевых исследований два зеркала скольжения на одной плоскости наблюдались в 12-ти точках наблюдения. Причем в некоторых случаях, возможно было говорить об относительной последовательности формирования этих зеркал скольжения. Например, если видно, что одно зеркало выглядит свежее, четче, а второе как будто «затерто». Или если одно некогда единое зеркало разбито трещиной на два отдельных, и на плоскости этой трещины зафиксированы следы смещения. 


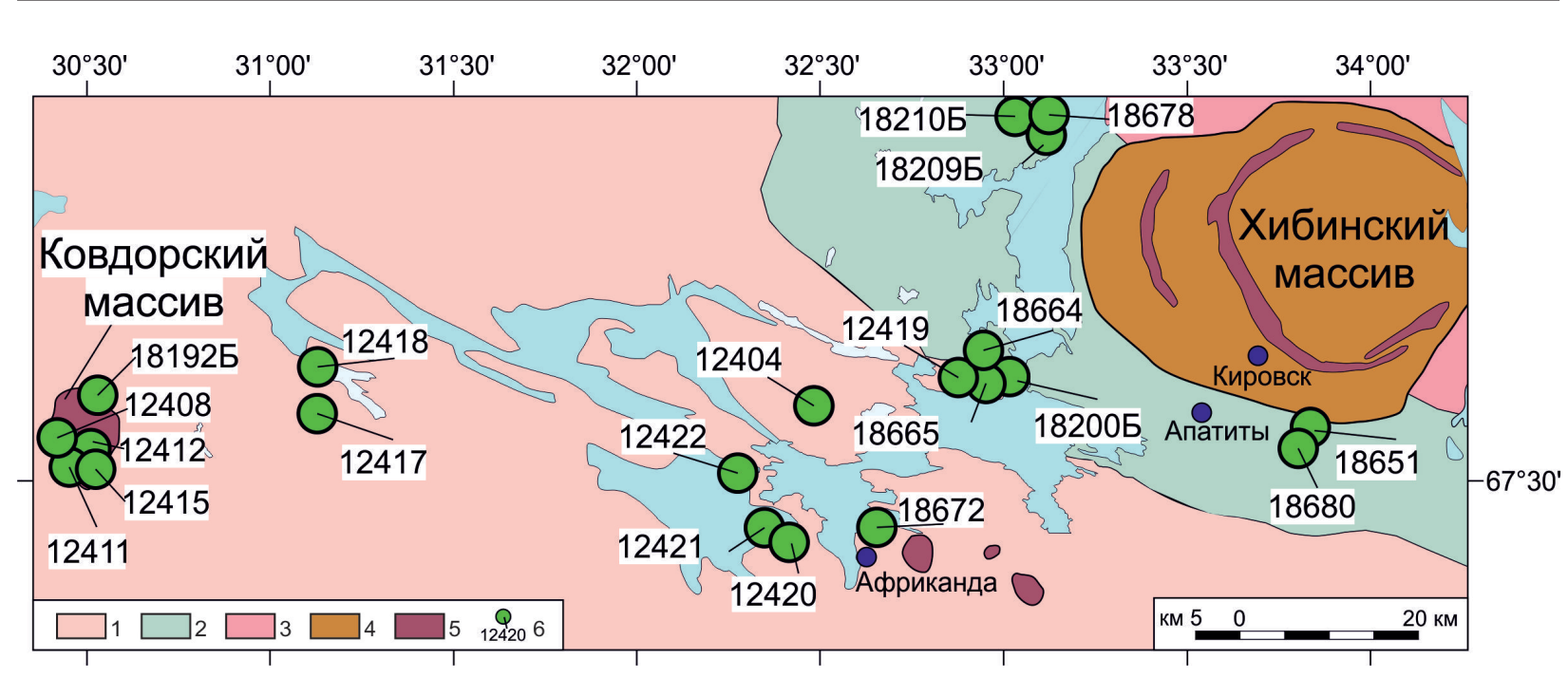

Рис. 1. Расположение точек наблюдений с двойными замерами (Государственная..., 2007).

1 - Беломорский пояс; 2 - Имандра-Варзугская шовная зона; 3 - Центрально-кольский блок; 4-5 - интрузивные щелочные массивы: 4 - щелочные ультрамафиты; 5 - фоидолиты, оливиниты, йолиты, нефелиновые сиениты; 6 - точки наблюдения.

Fig. 1. Location of observation points with double measurements (Gosudarstvennaya..., 2007). 1 - White Sea belt; 2 - Imandra-Varzug suture zone; 3 - Central Kola block; 4-5 - alkaline typhons: 4 - alkaline ultramafic; 5 - phoidolites, olivinites, yolites, nepheline syenites; 6 - observation point.

Все замеры зеркал скольжения с двумя направлениями штриховки были собраны в отдельную базу, после чего все «двойные» замеры были вынесены на круговую диаграмму и проанализированы с помощью структурно-парагенетического метода Расцветаева Л.М. и метода катакластического анализа Ребецкого Ю.Л (Расцветаев, 1987; Ребецкий и др., 2017). Структурно-парагенетический метод заключается в выделении закономерных и повторяющихся сочетаний тектонических нарушений разной морфологии и ориентировки, но близкого возраста и генезиса. Эти парагенетически связанные дизъюнктивы образуют определенные структурные рисунки, изучение которых позволяет определить кинематические (перемещение), тектонодинамические (поле напряжений) и реологические особенности дизъюнктивной деформации. Метод катакластического анализа разрывных смещений основан на анализе данных о зеркалах скольжения и позволяет определить ориентацию главных осей тензора напряжений и вид тензора, рассчитать нормированный тензор сейсмотектонических деформаций, а также определить нормированные величины эффективного и максимального касательного давлений. Все расчеты производятся в автоматическом режиме в программе STRESSgeol.

Для простоты описания полюсов плоскостей зеркал скольжений в некоторых случаях они будут именоваться просто «взброс», «сброс», «правый сдвиг» и т.д.

\section{Результаты исследования}

Все найденные двойные замеры, вынесенные на общую диаграмму показаны на рисунке 2 «Общая». Из общей диаграммы получены диаграммы «А» и «Б»: диаграмма «А»- индикаторы деформаций, про которые есть указание на их относительный древний возраст, диаграмма «Б» - все остальные.

Под № 1 находится зеркало скольжения со взбросовым смещением, рядом № 2 - взброс или сброс. Условно и его можно отнести к взбросам. Под № 3 находится сброс, а севернее - правый сдвиг со сбросовой компонентой. Для такого положения взброса, сброса и правого сдвига ось максимального сжатия ориентирована в направлении (СЗ-ЮВ) (северо-запад - юго-восток), а ось растяжения соответственно северо-восток - юго-запад.

На диаграмме «Б» показаны все остальные индикаторы деформаций: и те, про которые есть информация об их «молодом» возрасте, и просто двойные на одной плоскости. 


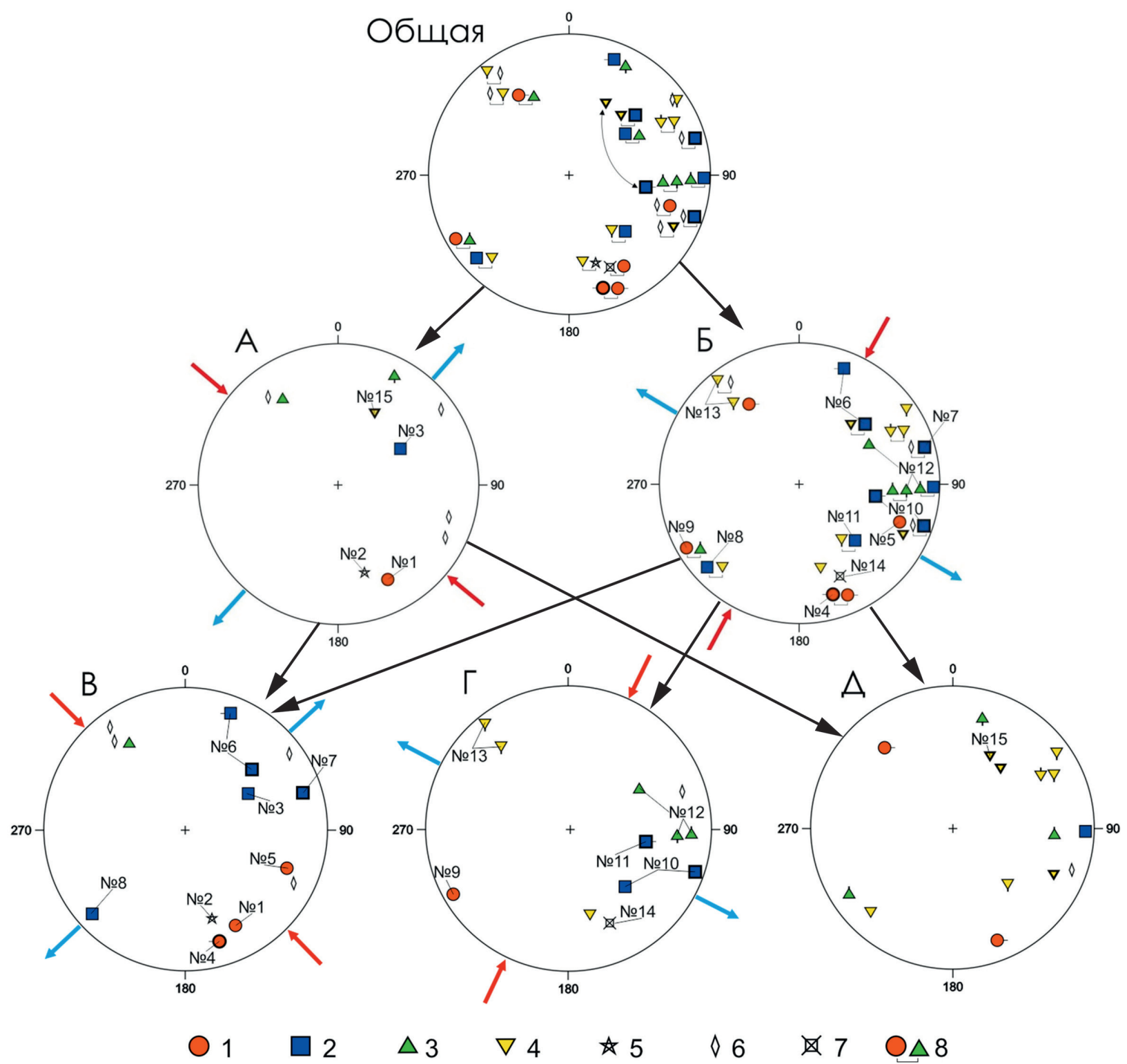

Рис. 2. Круговые диаграммы, показывающие положение полюсов плоскостей геологических индикаторов деформаций в центральной части Кольского полуострова. На диаграмме «А» показаны относительно «древние» индикаторы по виду, по структурному соотношению, на диаграмме. «Б» - «молодые» индикаторы по виду, по структурному соотношению, а также все остальные двойные, про которые нет информации. Диаграмма «В» - «древние», образовавшиеся в поле напряжений северо-западного сжатия. Диаграмма «Г»- «молодые», образовавшиеся в поле напряжений северо-восточного сжатия. Диаграмма «Д»- все остальные. Пояснения в тексте. Стереографическая проекция на верхнюю полусферу.

1-8 - полюса плоскостей дизъюнктивов: 1 - взброс; 2 - сброс; 3 - правый сдвиг; 4 - левый сдвиг; 5 - не определенной кинематики вертикального смещения (сброс-взброс); 6 - не определенной кинематики горизонтального смещения (сдвиг); 7 - отрыв; 8 - два дизъюнктива, расположенные на одной плоскости.

Fig. 2. Circular diagrams showing the position of the poles of the planes of geological indicators of deformations in the central part of the Kola Peninsula. The diagram «A» shows relatively «ancient» indicators by type, by structural ratio, in the diagram «Б» - «young» indicators by type, by structural ratio, as well as all other double indicators, about which there is no information. Diagram «B $»-\langle$ ancient», formed in the stress field of the north-west compression. Diagram «Г»- «young» formed in the stress field of the north-eastern compression. Diagram «Д»-all the others. Explanations in the text. Stereographic projection on the upper hemisphere.

1-8 - poles of the disjunctive planes: 1 - reverse fault; 2 - normal fault; 3 - right strike-slip fault; 4 - left strike-slip fault; 5 - undefined kinematics of vertical displacement (reverse-normal fault); 6 - undefined kinematics of horizontal displacement (strike-slip fault); 7 - breakaway; 8 - two disjunctives located on the same plane. 
При северо-западном сжатии и северо-восточном растяжении могли образоваться взбросы № 4 и № 5, и сбросы № 6, 7 и № 8. На диаграмме «В» показаны все дизъюнктивные нарушения, образованные в поле напряжений северо-западного сжатия.

Рассмотрим диаграмму «Б». Предположим, что ось максимального сжатия ориентирована в северо-восточном направлении (СВ-Ю3), а ось максимального растяжения - в северо-западном направлении (СЗ-ЮВ) и выделим следующие структурные парагенезы.

Такой ориентировки максимального сжатия хорошо соответствует взброс № 9, сбросы № 10 и № 11 также хорошо соответствуют юго-восточному и северо-западному растяжению. Правые сдвиги № 12 и левые сдвиги №1 3 тоже отвечают полю напряжения северо-восточного сжатия (рис. 2, диаграмма «Г»).

Отрывная минеральная корочка (№ 14, диаграмма «Б») была замечена на плоскости трещины поверх борозд зеркала скольжения взбросовой кинематики (№ 1, диаграмма «А»). Бесспорно, что эта отрывная структура более молодая и в свою очередь хорошо объясняется растяжением в югозападном направлении.

Зеркало скольжения сбросового типа № 11 зафиксировано авторами на западном берегу озера Большая Имандра в Кварцитовом карьере. Смещение по нему разделило другое зеркало скольжения (№ 15, диаграмма «А») с определенной кинематикой левый сдвиг на три части (рис. 3). Такое смещение не могло произойти в один акт деформации: сначала было левосдвиговое смещение по единой плоскости, а позже эта плоскость была разделена и дезинтегрирована сбросовыми смещениями. Следовательно этот сброс скорее всего относится к более молодым структурам.

Однако большим вопросом остается тот факт, что данный левый сдвиг нельзя отнести ни к первому ни к второму варианту ориентировки главных осей напряжения. На диаграмме «Д» показаны полюса плоскостей тех зеркал скольжения, которые не могли образоваться ни при северозападном сжатии, ни при северо-восточном. Это могут быть следы некого древнего поля напряжений, а может быть и ошибка определения.

В результате расчета методом катакластического анализа применительно к этим зеркалам скольжения получено три локальных стресс-состояния. В первом этапе ось максимального сжатия

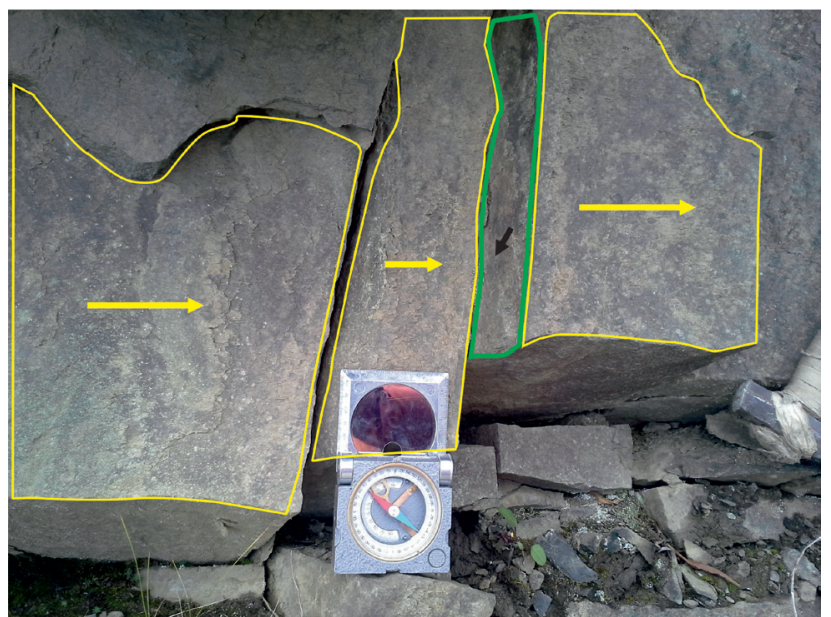

Рис. 3. Зеркало скольжения с левосдвиговым смещением (желтые стрелки) нарушено трещинами, на плоскости которых наблюдается сбросовая кинематика смещения. Кварцитовый карьер, западный берег оз. Большая Имандра, точка наблюдения 18209 Б.

Fig. 3. The slickenside with left-strike-slip displacements (yellow arrows) is broken by cracks, on the plane of which there is a normal fault. Quartzite quarry, west shore of lake Bol'shay Imandra, observation point 18209 Б.

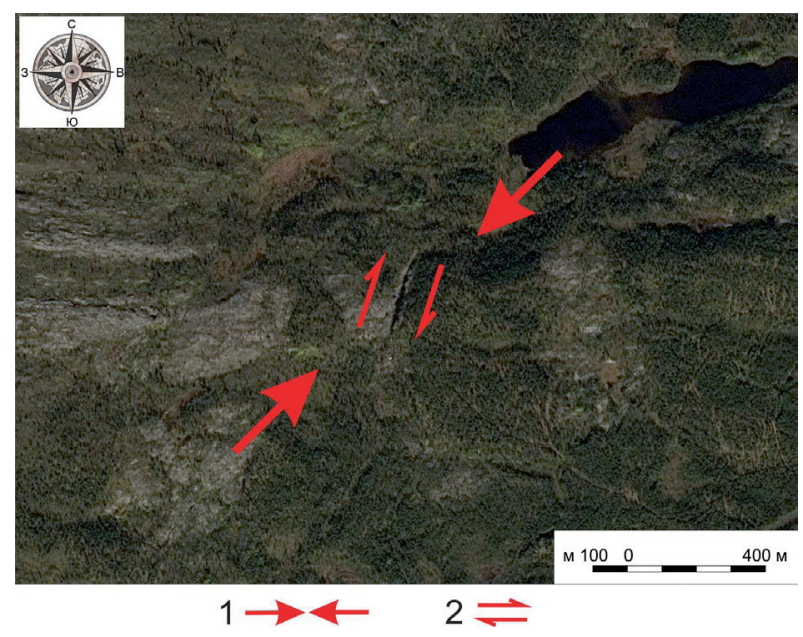

Рис. 4. Сейсморазрыв западнее озера Экоостровская Имандра с правосдвиговой кинематикой. 1 - ориентировка осей максимального сжатия $\sigma_{3 \text {; }}$ 2 - относительное смещение бортов разрыва.

Fig. 4. Seismic fracture west of the lake Ekostrovskaya Imandra with right strike-slip kinematics.

1 - orientation of the axes of maximum compression $\sigma 3$; 2 - relative displacement of the sides of the fracture. 
ориентирована на северо-запад, ось максимального растяжения - на северо-восток. Обе оси имеют небольшой угол погружения. Во втором этапе ось максимального сжатия ориентирована на югозапад, а ось максимального растяжения - на юго-восток, оси также погружаются относительно полого. В третьем этапе ось максимального сжатия довольно круто погружается на юг, а ось максимального растяжения почти горизонтальна, ориентирована на запад.

В подтверждение относительной молодости структур, образованных при северо-восточном сжатии существует один факт. Западнее озера Экоостровская Имандра около 20 лет назад была обнаружена разломная зона. Эта зона представляет собой сейсморазрывы, образующие эшелонированную систему отдельных сегментов (азимут простирания 10-25 ) протяженностью около 10 км.

Данный разрыв был комплексно изучен в работах (Николаева, 2018) и довольно точно определено время его активизации в поздне- и послеледниковое время. Всего выделено три этапа сильных сейсмических воздействий: 13.5 тыс. лет назад, 10.3 - 7.1 тыс. лет назад и 2.5 тыс. лет назад. Активизация разлома выражалась землетрясениями с магнитудой $\mathrm{M}=6$.

Также в работах (Николаева, 2018; Бондарь, 2019) различными методами определена кинематика разрыва: правый взбросо-сдвиг.

Правый сдвиг такого простирания может образоваться только в том случае, если оси максимального горизонтального сжатия будут ориентированы в направлении северо-восток - юго-запад (рис. 4).

\section{Выводы}

Таким образом, в центральной части Кольского полуострова зафиксированы следы двух региональных полей напряжений - северо-западного сжатия и северо-восточного сжатия. Есть все основания утверждать, что поле напряжений северо-восточного сжатия моложе, относительно поля напряжений северо-западного сжатия, на что указывают ряд тектонических структур и парагенезов малых структурных форм. С чем связано это поле напряжений пока не выяснено, для этого требуются дальнейшие исследования.

\section{Литература}

1. Бондарь И.В., Гордеев Н.А., Маринин А.В., Бондарь В.В. Деформационные структуры западного борта впадины оз. Имандра // Современная тектонофизика. Методы и результаты. Материалы шестой молодежной тектонофизической школы-семинара. Институт физики Земли РАН, Москва. М. Изд-во: ИФЗ PAH. 2019. C. 86-90.

2. Государственная геологическая карта Российской Федерации. Масштаб $1: 1000000$ (третье поколение). Серия Северо-Карско-Баренцевоморская. Лист R-(35), 36. Мурманск. Объяснительная записка. СПб.: Картографическая фабрика ВСЕГЕИ. 2007. 281 с.

3. Расцветаев Л.М. Парагенетический метод структурного анализа дизъюнктивных тектонических нарушений // Проблемы структурной геологии и физики тектонических процессов. М. Изд-во: ГИН АН CCCP. 1987 a. C. $173-235$.

4. Ребецкий Ю.Л., Сим Л.А., Маринин А.В. От зеркал скольжения к тектоническим напряжениям. Методы и алгоритмы. М. Изд-во: ГЕОС. 2017. 225 с.

5. Николаева С.Б., Никонов А.А., Шварев С.В., Родкин М.В. Детальные палеосейсмогеологические исследования в бортовой зоне впадины оз. Имандра (Кольский регион): новые подходы и результаты // Геология и геофизика. 2018. Т. 59 (6). C. 866-880. DOI: 10.15372/GiG20180608. 